Original article

\title{
Floral biology, nectar secretion pattern and fruit set of a threatened Bignoniaceae tree from Brazilian tropical forest
}

\author{
Camila Vaz Souza ${ }^{\mathrm{a}}$, Massimo Nepi ${ }^{\mathrm{b}}$, Silvia Rodrigues Machado ${ }^{\mathrm{c}}$, Elza Guimarães ${ }^{\mathrm{c}, *}$ \\ a Graduation Program in Biological Sciences (Botany), São Paulo State University (Unesp), Institute of Biosciences, Botucatu, SP, 18618-970, Caixa Postal \\ 510, Brazil \\ ${ }^{\mathrm{b}}$ Department of Life Sciences, University of Siena, Via P. A. Mattioli 4, 53100 Siena, Italy \\ ${ }^{c}$ Department of Botany, São Paulo State University (Unesp), Institute of Biosciences, Botucatu, SP, 18618-970, Caixa Postal 510, Brazil
}

\section{A R T I C L E I N F O}

\section{Article history:}

Received 1 July 2016

Received in revised form 9 December 2016

Accepted 15 December 2016

Edited by Stefan Dötterl

Available online 21 December 2016

\section{Keywords:}

Fruit set

Melittophily

Nectar secretion pattern

Nectar sugar composition

Zeyheria tuberculosa

\begin{abstract}
A B S T R A C T
Zeyheria tuberculosa, a Bignoniaceae tree that occurs in a broad latitudinal range in Brazilian forests, is a threatened species of seasonal tropical forest. It is crucial to enhance the knowledge on this species' floral biology, since interactions related to reproduction of plants are critical for the long term maintenance of their populations. Thus, we investigated the sexual reproduction and floral biology of $Z$. tuberculosa, including nectar features, aiming to understand the ecological processes associated to this mutualistic plant-animal interaction in the current modified landscape. For this, we performed experiments under natural conditions and in the laboratory. All the evaluated plants were self-incompatible. Zeyheria tuberculosa was pollinated by Bombus pauloensis, a medium-sized bee, and offered hexose-rich nectar as resource. Flowers were also visited by small-sized bee species, Trigona spinipes, that acted as pollen thief, and Pseudoaugochlora pandora and P. graminae that acted as nectar thieves. These three bee groups exhibited temporal separation in the peak of visits throughout the day. The peak of pollinator visits occurred firstly, which may allow the pollinator to access nectar and pollen loads before they are exploited by thieves. However, bee pollinator visits were scarce, and this fact, associated to the self-incompatibility of Z. tuberculosa, may explain the low fruit set registered in the studied plants. It could be of special concern for this threatened species maintenance in the medium and long term, which depends on the offspring originated by sexual reproduction.
\end{abstract}

(c) 2016 Elsevier GmbH. All rights reserved.

\section{Introduction}

Floral characteristics directly related to the attraction of pollinators are essential to the mutualism maintenance, ensuring the transference of pollen grains and therefore reproductive success in outcrossing species (Herrera, 1990, 1996). The relationship between plants and pollinators is established by means of rewards that usually fit the animal's primary needs, such as feeding (Faegri and Van Der Pijl, 1979). Food urge is related to the majority of flower visits, being nectar the main floral energy source to pollinators (Willmer, 2011).

Nectar is the most important floral resource for the majority of Bignoniaceae, which is a family predominately composed by species having sympetalous nectariferous and zoophilous flow-

\footnotetext{
* Corresponding author.

E-mail addresses: camilavaz@ibb.unesp.br (C.V.Souza), massimo.nepi@unisi.it (M. Nepi), smachado@ibb.unesp.br (S.R. Machado), eguimaraes@ibb.unesp.br (E. Guimarães).
}

ers (Gentry, 1992; Bittencourt and Semir, 2004; Gottsberger and Silberbauer-Gottsberger, 2006; Guimarães et al., 2008; Galetto, 2009). It is fundamental to know floral nectar parameters such as volume and concentration, and their time-scale variation in order to understand the behaviour of floral visitors and the complexity of plant-animal relationships, especially the requirements and preferences of pollinators (Baker and Baker, 1975; Galetto and Bernardello, 2005).

Brazil is the diversity centre of Bignoniaceae (Gentry, 1980; Lohmann and Ulloa, 2007), and although plants of this family attract a large spectrum of pollinators, such as butterflies, moths, bats, and hummingbirds (Gentry, 1990), there is a predominance of mediumand large-sized bees as pollinators (Gentry, 1974; Gottsberger and Silberbauer-Gottsberger, 2006). The reproductive biology of Zeyheria tuberculosa, a Bignoniaceae tree that occurs in a broad latitudinal range in Brazilian forests (Gentry, 1992), is still unknown, although its floral traits fit pollination by bees (Gentry, 1992; Lohmann and Pirani, 1996; Alcantara and Lohmann, 2010). It is crucial to enhance the knowledge on this species' floral biology because 
Z. tuberculosa is included as vulnerable in the red list of threatened species of the Brazilian flora (Martinelli and Moraes, 2013), and in the International Union for Conservation of Nature (IUCN) red list of threatened species. This means that this taxon is facing a high risk of extinction in the wild in the medium-term future due to the extensive destruction of natural ecosystems in which this species occurs, and in its consequent population decline (World Conservation Monitoring Centre, 1998). Biotic interactions related to the reproduction of plants are critical for the long term maintenance of populations (Kearns and Inouye, 1997; Aguilar et al., 2009; Brudvig et al., 2015), especially because they may result in important bottom-up effects in the ecosystem (Chapin III et al., 2002). Hence, studies on sexual reproduction of $Z$. tuberculosa in the current modified landscape may help us to understand the ecological processes comprising this mutualistic plant-animal interaction.

Thus, the aim of this study was to investigate the floral biology and sexual reproduction of $Z$. tuberculosa. More specifically we aim to: (1) test if this species is dependent on a pollen-transferring vector for sexual reproduction; (2) assess flower-pollinator relationships and eventually confirm if bees are the main pollinators of Z. tuberculosa; (3) describe floral nectar features, using nectar volume, concentration and composition as descriptors; (4) determine fruit set of $Z$. tuberculosa in natural conditions.

\section{Material and methods}

\subsection{Study sites and organism}

From January to July in 2014 and 2015, we studied four developed trees in reproductive stage, sampling all the four plants in both years. In 2014 we collected data on floral biology, floral visitors, nectar features and fruit set; in 2015 we expanded the floral visitors sampling. We only sampled four individuals because of the current scarcity of $Z$. tuberculosa plants in natural ecosystems in the study region. This scenario is due to the destruction of its habitat (Luz and Ferreira, 1985) and to the intensive exploitation of its wood until recently (Carvalho, 2005). The sampled plants occurred in disturbed areas, close to remnants of tropical forest located in Pratânia (plants 1 and 2) and Botucatu (plants 3 and 4) municipalities, São Paulo state, South-eastern Brazil (Table 1). According to Köppen's classification, the region's climate is Cwa, mesothermal with rainy summer and dry winter (Cunha and Martins, 2009).

Zeyheria tuberculosa (Vell.) Bureau ex Verl, occurs in seasonal forests from southeast Brazil, São Paulo state, until northeast Brazil, Ceará state (Lohmann and Pirani, 1996). It is a deciduous species; reaching $20-30 \mathrm{~m}$ of height with thick vertically fissured bark; opposite leaves; terminal panicle inflorescence; campanulate brown or tan to yellowish flowers on the outside and orange to somewhat red or purplish on the inside, without a narrow basal tube, didynamous stamens with divaricate anther thecae, broadly obovoid ovary, densely stellate-pilose disk not obviously differentiated from the ovary base; broadly obovoid to round capsule fruit with tannish stellate tomentose surface; thin seeds, with a distinctly verrucose surface surrounded by broad hyalinemembranaceous wing (Gentry, 1992; Lohmann and Pirani, 1996).

Vouchers of the studied plants were collected and deposited in the 'Irina Delanova Gemtchujnicov' Herbarium (BOTU) from the São Paulo State University (Unesp), Institute of Biosciences, Botucatu, SP, Brazil, under the numbers 30818 and 30819.

\subsection{Floral biology}

During the flowering period (Jan-Feb), we monitored 40 flowers, 10 per plant $\left(\mathrm{N}_{\text {plants }}=4\right)$ throughout the day to detect the time of flower opening, the duration of anthesis, the colour and the dimen-

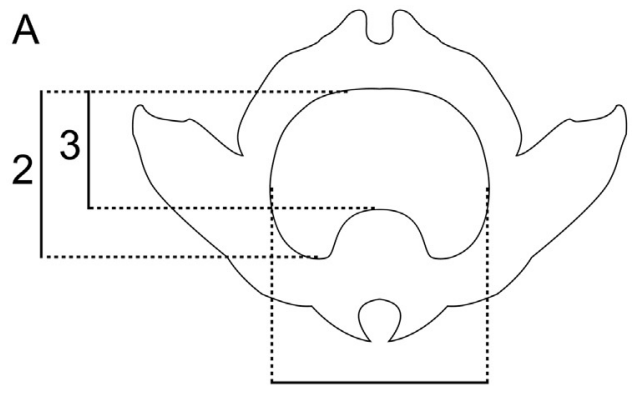

1

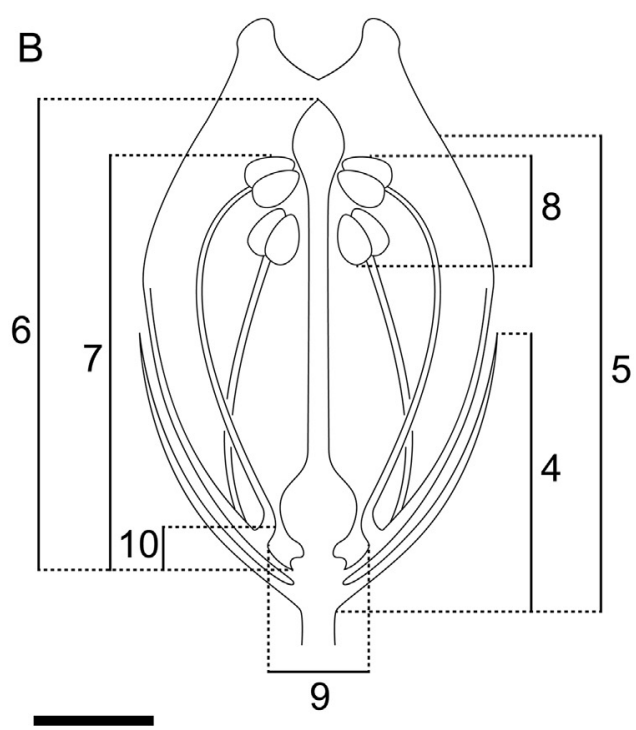

Fig. 1. Dimensions of Zeyheria tuberculosa floral traits. (A) Frontal view of a Z. tuberculosa flower, showing: (1) diameter at the corolla mouth (horizontally to the soil), (2) diameter of the zygomorphic plane at the corolla mouth (vertically to the soil), and (3) diameter of the corolla constriction region. (B) Longitudinal section of a $Z$. tuberculosa flower, showing: (4) calyx length, (5) corolla tube length, (6) distance between the upper portion of the stigma and the nectar chamber's basis, (7) distance between the of the top of the longest stamen and the nectar chamber's basis, (8) length of the pollen deposition area, (9) diameter of the nectar chamber, and (10) length of the nectar chamber. Scale bar: $3 \mathrm{~mm}$.

sions of the floral elements. Besides, in the same set of flowers, we tested stigma receptivity using hydrogen peroxide $\left(\mathrm{H}_{2} \mathrm{O}_{2}\right)$ according to Dafni et al. (2005) and estimated viability of pollen grains using acetic carmine as a vital stain (Radford et al., 1974).

We performed morphometric analyses on 70 flowers from three plants of $Z$. tuberculosa aiming to describe the floral morphology and the dimensions associated to the pollinators' body dimensions, and to the placement of pollen load on the pollinators' body. For this, we measured the following traits: (1) diameter at the corolla mouth (horizontally to the soil), (2) diameter of the zygomorphic plane at the corolla mouth (vertically to the soil), (3) diameter of the corolla constriction region, (4) calyx length, (5) corolla tube length, (6) distance between the upper portion of the stigma and the nectar chamber's basis, (7) distance between the top of the longest stamen and the nectar chamber's basis, (8) length of the pollen deposition area, (9) diameter of the nectar chamber, and (10) length of the nectar chamber (Fig. 1A-B).

To investigate if $Z$. tuberculosa was self-compatible, we performed manual pollination tests. For that, in each individual $\left(\mathrm{N}_{\text {plants }}=4\right)$, we bagged five inflorescences having pre-anthesis buds, to avoid any previous contact with floral visitors, and we tested for self-compatibility using functional flowers of first (newly opened) and second (24-h flowers) days of anthesis. We performed 
Table 1

Characterization of the studied plants of Zeyheria tuberculosa (Bignoniaceae) and of the study sites located in Pratânia and Botucatu municipalities, São Paulo state, Brazil.

\begin{tabular}{|c|c|c|c|c|}
\hline Plants & $\operatorname{High}(\mathrm{m})$ & Treetop diameter (m) & Geographic coordinates & Study sites \\
\hline 1 & 20 & 15 & $22^{\circ} 45^{\prime} 59^{\prime \prime} \mathrm{S} 48^{\circ} 38^{\prime} 10^{\prime \prime} \mathrm{W}$ & $\begin{array}{l}\text { moderately disturbed } \\
\text { areas, near to a forest } \\
\text { remnant with } \\
\text { around } 1300 \mathrm{~m}^{2} \text {, } \\
\text { inserted in a sugar cane } \\
\text { matrix }\end{array}$ \\
\hline 2 & 15 & 7 & $22^{\circ} 45^{\prime} 56^{\prime \prime} \mathrm{S} 48^{\circ} 38^{\prime} 08^{\prime \prime} \mathrm{W}$ & \\
\hline 3 & 12 & 5 & $22^{\circ} 53^{\prime} 14^{\prime \prime} \mathrm{S} 48^{\circ} 29^{\prime} 26^{\prime \prime} \mathrm{W}$ & $\begin{array}{l}\text { moderately disturbed area, close to a } \\
\text { remnant with } 2900 \mathrm{~m} 2 \text {, original forest } \\
\text { fragmented into small patches }\end{array}$ \\
\hline 4 & 10 & 4 & $22^{\circ} 54^{\prime} 31^{\prime \prime} \mathrm{S} 48^{\circ} 26^{\prime} 14^{\prime \prime} \mathrm{W}$ & $\begin{array}{l}\text { heavily disturbed area, close to human } \\
\text { settlements, having just one small } \\
\text { remnant }\left(300 \mathrm{~m}^{2}\right) \text { in the } \\
\text { neighbourhood }\end{array}$ \\
\hline
\end{tabular}

manual pollinations using flowers from different inflorescences of the same plant. We transferred pollen from the anthers to the stigmas in three treatments: (a) pollen from newly opened flowers to the stigmas of 24-h flowers, (b) pollen from newly opened flowers to the stigmas of newly opened flowers (c) pollen from 24-h flowers to stigmas of 24-h flowers. After the hand-pollination experiments, the inflorescences were re-bagged and daily observed until the development of fruits or flowers' abscission.

\subsection{Floral visitors}

We made focal observations, according to Potts (2005) and analysed photographs and videos to check for the species of flower visitors, their behaviour, and the time and frequency of flower visits per plant. We made all the records for $Z$. tuberculosa from $0500 \mathrm{~h}$ to $2200 \mathrm{~h}$, totalling $174 \mathrm{~h}$ of field observations, evenly distributed among the sampled plants (about $40 \mathrm{~h}$ per plant) and over 15 nonconsecutive days. In each day, we monitored the plants for 6-12 consecutive hours, covering the entire daylight hours. We carried out a Local Weighted Regression (LOESS) and 95\% confidence intervals, in R v. 3. 1. 1 (R Development Core Team, 2016), to describe the variation of bee visitation throughout the day $(0700-1800 \mathrm{~h}$, period during which visits were registered). We used the number of visits per hour as the response variable and the time of day in which visits happened as the predictor variable. We used the days as sampling units $\left(\mathrm{N}_{\text {days }}=11\right)$.

We performed morphometric analysis of all bee species sampled in this study ( $\mathrm{N}_{\text {Bombuspauloensis }}=10$ specimens, $\mathrm{N}_{\text {Trigonaspinipes }}=1 \mathrm{spec}-$ imen, $\mathrm{N}_{\text {Pseudoaugochlorapandora }}=1$ specimen, $\mathrm{N}_{\text {P.graminea }}=1$ specimen $)$. For this, we measured bee's body length, proboscis length (from the proximal portion of the galeas to the distal portion of the glossa), dorsiventral thorax thickness, latero-lateral thorax thickness, head length, and head lateral size. Additionally, we measured the distance between the top of the head and the end of the abdomen in order to classify the bees in the following categories, based on their relative sizes: small-sized bees $<10 \mathrm{~mm}$, and medium-sized bees between 10 and $15 \mathrm{~mm}$. We collected one specimen of each bee species from focal trees and obtained the other nine pollinator bees from Dr. Guimarães' Pollinator Collection ('Ecology and Evolution of Plant-Animal Interactions Laboratory' from the Department of Botany, São Paulo State University (Unesp), Institute of Biosciences, Botucatu, SP, Brazil) that is composed by specimens collected in the same region of the present study.

\subsection{Pattern of floral nectar secretion during anthesis}

To evaluate the natural nectar production pattern during anthesis we used two nectar parameters: volume $(\mu \mathrm{L})$ and concentration (\%, weight/weight). We calculated the milligrams of total sugar per flower (mgS) using data on nectar volume and concentration after conversion of the concentration from $\% \mathrm{w} / \mathrm{w}$ to $\mathrm{mg}$ of sugar/microliter of nectar, according to the equation provided by Galetto and Bernardello (2005). For that, we took, in a nonsystematic way, fifteen inflorescences per individual $\left(\mathrm{N}_{\text {plants }}=4\right)$, containing five pre-anthesis buds each $\left(\mathrm{N}_{\text {flowers/plant }}=75\right)$, totalling 300 flowers sampled in this natural experiment. In order to obtain data on the potential nectar production per flower and per plant without nectar depletion by floral visitors, we protected all the inflorescences with bridal veil bags. We measured nectar volume $(\mu \mathrm{L})$ using calibrated syringes; and concentration of solutes (\%) using a manual refractometer (Eclipse $45-81$ : 0-50\% sucrose $\mathrm{w} / \mathrm{w}$ ). We performed these measurements at three moments (100 flowers per sampling period, 25 flowers per plant): at the beginning of the first day of anthesis (recently opened flowers), at the end of the first day of anthesis ( $12 \mathrm{~h}$-flowers), and at the end of the second day of anthesis ( $36 \mathrm{~h}$-flowers), each time using a new set of flowers. The assessment made in these three schedules allowed us to observe: (1) if there was nectar available to floral visitors at the beginning of anthesis and, if so, how much nectar was available at that time; (2) how much nectar was available per flower at the end of the first day of anthesis; and (3) how much nectar was available per flower at the end of the second day of anthesis.

We used two-way factorial ANOVA to test the effects of time (factor 1 with three levels "recently opened flowers", "12-h flowers" and "36-h flowers"), plant (factor 2 with four levels "plant 1", "plant 2 ", "plant 3" and "plant 4") and their interaction on the response variables "nectar volume", "nectar concentration" and "milligrams of sugar". We tested each response variable separately. We performed post-hoc comparison of means per sampling time using Tukey HSD test for homogeneous groups. We performed these analyses with the software Statistica 12 (StatSoft, 2013).

Additionally, we counted the total number of flowers per inflorescence and estimated the number of inflorescences per individual to assess how much nectar a $Z$. tuberculosa tree can potentially produce per day, and during its entire flowering period, using the mean of the four plants.

\subsection{Nectar chemical composition}

We determined the floral nectar sugar composition on the first day of anthesis using nectar from flowers that were bagged at preanthesis stage with bridal veil bags $\left(\mathrm{N}_{\text {samples }}\right.$ of nectar $=8 ; 3$ samples from plant 1, 2 samples from plant 2, and 3 samples from plant 4 ). We stored the samples of nectar for sugar composition analysis in vials at $-20^{\circ} \mathrm{C}$. Prior to the analysis, we thawed the nectar samples to ambient temperature, and diluted them 1:25 in distilled water. Only then we analysed the samples' sugar content by High Performance Liquid Chromatography (HPLC). We used water 
as the mobile phase (MilliQ, $\mathrm{pH} 7$ ) with $0.5 \mathrm{~mL} / \mathrm{min}$ flow rate. We used a Waters Sugar-Pack I $(6.5-300 \mathrm{~mm})$ column maintained at $85-90^{\circ} \mathrm{C}$ to separate sugars and we identified them by a refractive index detector (Waters 2410). We injected twenty microliters of sample and standard solution (glucose, fructose and sucrose). Then, we calculated the concentration of each single sugar by comparing the area under the chromatogram peaks with standards using the software Clarity (DataApex).

\subsection{Fruit set}

We registered the number of flowers produced per tree $\left(\mathrm{N}_{\text {plants }}=4\right)$ during the entire blooming (Jan-Feb) by counting the number of flowers per inflorescence, and the number of inflorescences in $20 \%$ of each plant's treetop, and then, we estimated the total amount of flowers per plant. In July, we counted all the fruits produced per plant. We calculated the natural fruit set by the ratio between the number of fruits and the number of flowers produced by each plant.

\section{Results}

\subsection{Floral biology}

Flowering of $Z$. tuberculosa occurred in January-February (Fig. 2A). The flowers started opening at around $0700 \mathrm{~h}$. Although the beginning of anthesis was concentrated in the morning, we registered some few flowers opening throughout the day, until about $1700 \mathrm{~h}$. Each inflorescence had 9.3 \pm 2.7 first-day flowers per day, and the old flowers remained attached to the branches, even when they were no longer receptive. The flowers were functional at least for two days, and on the first day the flowers had yellow colour, on the second day they became reddish (Fig. 2B). Such colour change occurred in turgid flowers, in the corolla as a whole, and it was remarkably evident in the inner surface of the floral tube. The flowers of $Z$. tuberculosa had a campanulate corolla and the dimensions of the floral elements are reported in Table 3. The upper and lateral petals were slightly or considerably curved back, whereas the lower petal was consistently straightened forward, creating an area that could be used as landing platform by the bees (Fig. 2C). Also, the lower petal possessed an elevated area that created a constriction region, which reduced the tube diameter exactly under the reproductive structures (anthers and stigma) (Figs. $1 \mathrm{~A}, 2 \mathrm{C}$ ). The three lower petal lobes showed nectar guides evinced by a reddish line followed by a groove that originated in the tube opening and went down to the base, towards the nectar chamber (Fig. 2C).

When the flowers opened, the pollen was already exposed and the stigma lobes were separated. The stigma remained receptive at least during the first two days of anthesis, reacting positively to the hydrogen peroxide test. The stigma was sensitive, and closed when touched, however it re-openned gradually. The anthers dehisced completely exposing yellowish clustered pollen grains. The mean viability of pollen grains was $86 \pm 17.2 \%$. In this species, nototribic pollen deposition on the pollinator's body occurred following a specific sequence: firstly, the pollinator contacted the receptive stigma surface (if the lobes were open), and then, it contacted the anthers' area; if there was pollen available, it could adhere to bee's body and be transported to the next flower (Figs. $1 \mathrm{~B}, 2 \mathrm{C}$ ). We registered no fruit set in manually self-pollinated flowers.

\subsection{Floral visitors}

All visitors observed on Z. tuberculosa flowers belonged to Hymenoptera. We classified small and medium-sized bees in distinct functional groups according to their behaviour (pollinators, pollen thieves and nectar thieves, Table 2). Insects visited the flowers with variable frequency during day time (Fig. $3 \mathrm{~A}-\mathrm{C}$ ).

The medium-sized bee species, Bombus pauloensis, was considered the only legitimate visitor because it contacted male and female reproductive structures during visits due to its body dimensions (Table 4) and visit behaviour (Fig. 2D). This bee species visited approximately five flowers per inflorescence and approximately 15 flowers in a sequence (min. 3-max. 20 flowers) before leaving a tree. These bees entered deeply into the corolla tube, with its head and thorax, apparently searching for nectar, spending an average of $10 \mathrm{~s}$ in each flower visit (min. 3 - max. $15 \mathrm{~s}$ per flower). When a bee entered a flower, its head and thorax (Fig. 2D-F) touched, at first, the receptive surface of the stigmatic lobes, and subsequently the anthers. When a bee left a flower, with the dorsal portion of its thorax covered with pollen, it touched only the sterile portions of the stigmatic lobes reducing pollen-stigma interference, characterizing an approach herkogamy. These bees' visits were more frequent during the morning, with a peak activity between 0800 and $1000 \mathrm{~h}$ (Fig. 3A), visiting both, first-day ( $70 \%$ of the visits, $\mathrm{n}=17$ visits) and second-day flowers (30\%), in an inflorescence per turn.

Among the small-sized bees, we just registered pollen and nectar thieves. Trigona spinipes was the only species classified as pollen thief due to its visit behaviour and body dimensions (Table 4 ). These bees inspected the flowers and entered the tube, on the anthers' level, and actively collected pollen with their first pair of legs, while cleaning their bodies and transferring pollen to their third pair of legs (Fig. 2G). This procedure lasted approximately $60 \mathrm{~s}$ per flower. Trigona spinipes bees were more frequent in the afternoon, with their activity peak from 14:00 to 16:00 (Fig. 3B).

We classified two species as nectar thieves, Pseudoaugochlora pandora and P. graminea (Fig. $2 \mathrm{H}$ ). The bees of both species showed similar behaviour during flower visits, entering deeply into the corolla tube, towards the nectar chamber and apparently gathering nectar. However, they were never observed contacting reproductive structures due to their reduced body size (Table 4) as compared to the flower dimensions (Table 3). Additionally, we did not observe stigma closure during the foraging of these bees. Due to the similar behaviour, size, morphology and colour of these bees it was not possible to identify to which species each observed specimen belonged. So, the data on the frequency of visits are presented for both species indistinctly and refers to the nectar thieves group. Pseudoaugochlora pandora and P. graminea were more frequent in the morning and at the end of the afternoon, showing two slight peaks from 9:00 to $10: 00 \mathrm{~h}$, and from $15: 00$ to $16: 00 \mathrm{~h}$ (Fig. 3C).

\subsection{Pattern of nectar secretion during anthesis and nectar sugar composition}

Nectar production in $Z$. tuberculosa started at pre-anthesis stage and continued until the second day of anthesis, with average nectar volume values of $1.6 \pm 0.3 \mu \mathrm{L}$, nectar concentration of $19.7 \pm 2.9 \%$, and milligrams of total sugar of $0.3 \pm 0.1 \mathrm{mgS}$. Nectar volume and concentration were affected by plant, time, and by the interaction between plant and time, however, we did not observe any interaction between time and plant for milligrams of sugar (Table 5).

Post-hoc comparisons (Tukey) showed that the nectar volume in recently opened flowers was significantly different from the volume found in flowers at the end of the first day of anthesis (12 h-flowers) and flowers at the end of the second day of anthesis, (36h-flowers) ( $p<0.01$ for all comparisons), with an apparent decrease at the end of the first day and an increase at the end of the second day (Fig. 4A). The same pattern was registered for concentration ( $p<0.002$ for all comparisons), but in general we registered a gradual concentration increase during the flowers' lifespan, with the exception of plant 1 , which showed a remarkable decrease in 

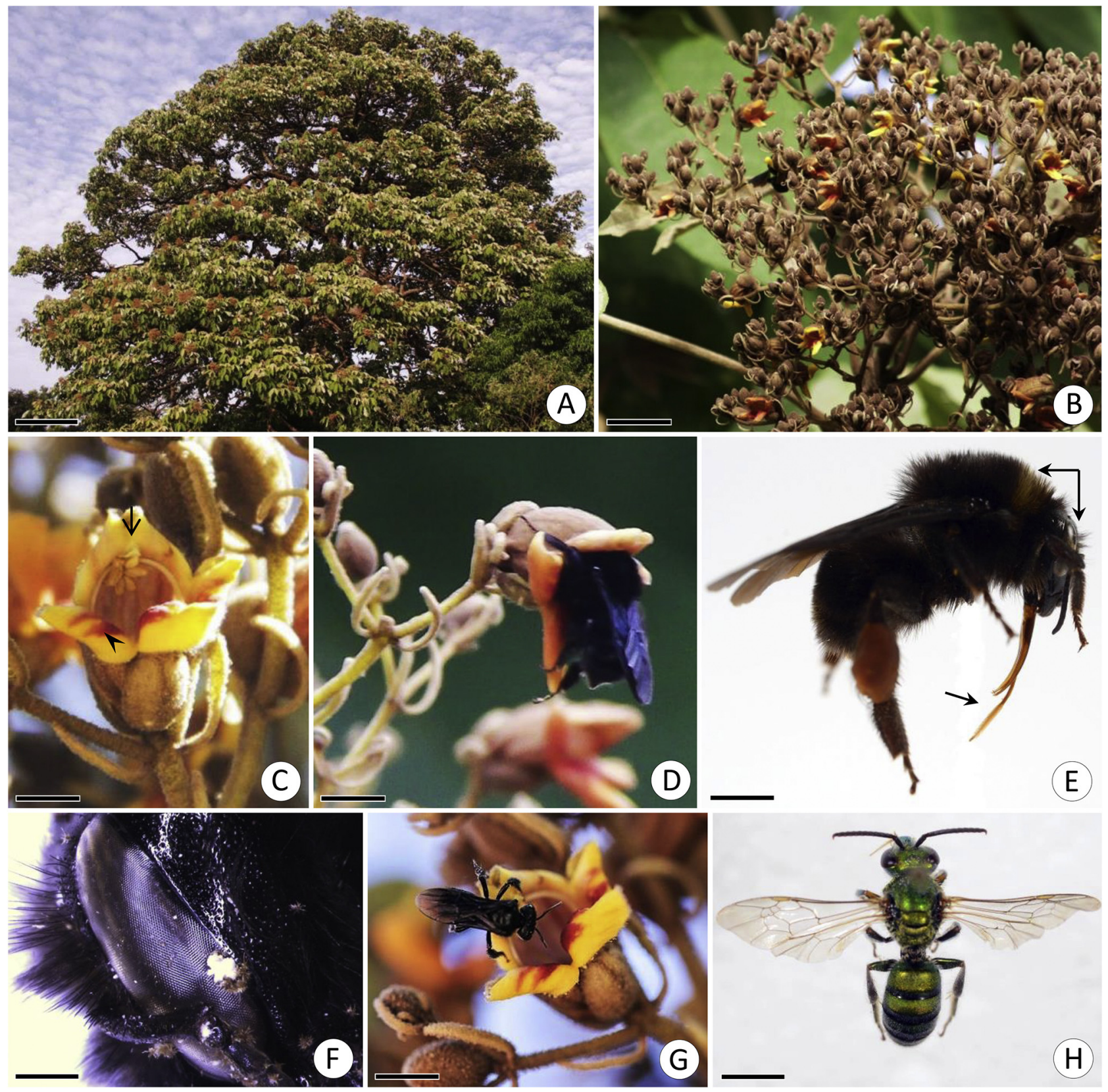

E

Fig. 2. Zeyheria tuberculosa flowers and floral visitors. (A) Flowering treetop. Scale bar: $1 \mathrm{~m}$. (B) Inflorescence with first- (yellow) and second-day (reddish) flowers. Scale bar: $2.5 \mathrm{~cm}$. (C) Recently opened flower showing herkogamy with separate stigma lobes (arrow), in an upper position, followed by the anthers, full of pollen. Note the reddish lines indicating nectar guides (arrow head) Scale bar: $5 \mathrm{~mm}$ (D) Bombus pauloensis legitimately visiting a second-day flower. Scale bar: $5 \mathrm{~mm}$. (E) Lateral view of Bombus pauloensis evincing the proboscis (single arrow) and the main site of pollen deposition in the bee's thorax and head (double arrow). Scale bar $=3 \mathrm{~mm}(\mathrm{~F})$ Detail showing a pollen mass deposited on the bee's eye. Scale bar $=0.5 \mathrm{~mm}$. (G) Pollen thief, Trigona spinipes, collecting pollen directly from the anthers. Scale bar: $5 \mathrm{~mm}$. (H) Nectar thief Pseudoaugochlora graminea. Scale bar: $3 \mathrm{~mm}$. (For interpretation of the references to colour in this figure legend, the reader is referred to the web version of this article.)

Table 2

Zeyheria tuberculosa visitors in patches of tropical seasonal forest, in Botucatu and Pratânia municipalities, São Paulo state, Brazil.

\begin{tabular}{|c|c|c|c|}
\hline Species & Visiting behavior & Foraged resource & Frequency $^{\mathrm{a}}$ \\
\hline \multicolumn{4}{|l|}{ APIDAE } \\
\hline Bombus pauloensis & Legitimate & Nectar & Low \\
\hline Trigona spinipes & Non-legitimate & Pollen & Low \\
\hline \multicolumn{4}{|l|}{ HALICTIDAE } \\
\hline Augochloropsis sp. & Non-legitimate & Nectar & Very low \\
\hline Pseudoaugochlora graminea & Non-legitimate & Nectar & Low \\
\hline
\end{tabular}

a Frequency: low $=$ on average $0.5-1.0$ visits per hour during the peak; very low $=$ on average $<0.5$ per hour during the peak. 
Table 3

Dimensions of Zeyheria tuberculosa floral traits $\left(\mathrm{N}_{\text {flowers }}=70, \mathrm{~N}_{\text {plants }}=3\right)$.

\begin{tabular}{|c|c|}
\hline Floral traits & Mean \pm sd $(\mathrm{mm})$ \\
\hline 1. Calyx length & $6.98 \pm 0.63$ \\
\hline 2. Corolla length & $15.26 \pm 0.80$ \\
\hline 3. Diameter at the corolla mouth (horizontally to the soil) & $7.12 \pm 0.78$ \\
\hline 4. Diameter of zygomorphic plan at the corolla mouth (vertically to the soil) & $5.09 \pm 0.49$ \\
\hline 5. Diameter of the corolla's constriction region & $3.06 \pm 0.46$ \\
\hline 6. Distance between the upper portion of the stigma and the nectar chamber's basis & $12.60 \pm 0.74$ \\
\hline 7. Distance between the top of the longest stamen and the nectar chamber's basis & $10.65 \pm 0.44$ \\
\hline 8. Length of the pollen deposition area & $3.00 \pm 0.38$ \\
\hline 9. Diameter of the nectar chamber & $1.82 \pm 0.22$ \\
\hline 10. Length of the nectar chamber & $0.95 \pm 0.098$ \\
\hline
\end{tabular}

Table 4

Body dimensions of $Z$. tuberculosa's bee visitors $\left(N_{B \text {.pauloensis }}=10, N_{\text {.spinipes }}=1, N_{P \text {.pandora }}=1, N_{P \text {.graminea }}=1\right)$.

\begin{tabular}{|c|c|c|c|c|}
\hline Bee traits & $\begin{array}{l}\text { Bombus pauloensis } \\
\text { mean } \pm \mathrm{sd}(\mathrm{mm})\end{array}$ & $\begin{array}{l}\text { Trigona spinipes } \\
(\mathrm{mm})\end{array}$ & $\begin{array}{l}\text { Pseudoaugochlora } \\
\text { Pandora } \\
(\mathrm{mm})\end{array}$ & $\begin{array}{l}\text { Pseudoaugochlora } \\
\text { graminea } \\
(\mathrm{mm})\end{array}$ \\
\hline Body length & $12.94 \pm 0.77$ & 6.04 & 7.59 & 9.49 \\
\hline Proboscis length & $5.90 \pm 0.91$ & 1.41 & 0.82 & 1.15 \\
\hline Thorax dorsiventral thickness & $5.90 \pm 0.48$ & 2.69 & 1.90 & 2.77 \\
\hline Thorax latero-lateral thickness & $5.52 \pm 0.27$ & 2.22 & 2.43 & 2.86 \\
\hline Head lengh & $3.14 \pm 0.35$ & 2.92 & 2.12 & 2.57 \\
\hline Head lateral size & $4.34 \pm 0.57$ & 2.60 & 2.29 & 2.72 \\
\hline
\end{tabular}

Table 5

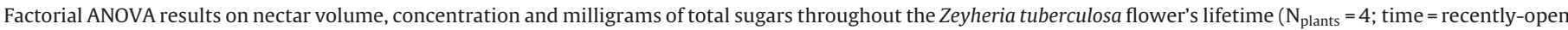
flowers, 12-h flowers and 36-h flowers).

\begin{tabular}{|c|c|c|c|c|c|c|c|c|c|}
\hline & \multicolumn{3}{|c|}{ Nectar volume } & \multicolumn{3}{|c|}{ Concentration } & \multicolumn{3}{|c|}{ Mg of total sugars } \\
\hline & df & $F$ & $p$ & df & $F$ & $p$ & df & $F$ & $p$ \\
\hline Plant & 3 & 9.313 & $<0.001$ & 3 & 15.07 & $<0.001$ & 3 & 21.12 & $<0.001$ \\
\hline Time & 2 & 9.603 & $<0.001$ & 2 & 21.05 & $<0.001$ & 2 & 12.54 & $<0.001$ \\
\hline Plant*Time & 6 & 2.871 & 0.0102 & 6 & 12.12 & $<0.001$ & 6 & 0.98 & 0.442 \\
\hline
\end{tabular}

nectar concentration from the first to the second day of anthesis (Fig. 4B).

Post-hoc comparisons for milligrams of sugars showed no significant difference between recently opened flowers and flowers at the end of the first day of anthesis ( $p=0.527)$, but showed a significant increase (Fig. 4C) in milligrams of sugars in flowers at the end of the second day of anthesis $(\mathrm{p}<0.001)$. We registered two plants producing significantly higher amounts of sugar per plant (Fig. 4D).

In order to estimate the total milligrams of sugar produced per plant/day, we registered a mean of $555 \pm 245$ flowers per inflorescence and estimated $553 \pm 647$ inflorescences per plant, which corresponds to a mean of $262,631 \pm 330,855$ flowers produced per plant during the flowering period; using these data we estimated a total sugar content per plant of $Z$. tuberculosa of $1.6 \pm 1.5 \mathrm{~g}$ of sugar per day, with a mean of $95.7 \pm 93.6$ g per plant throughout the entire flowering period, which lasted two months.

Floral nectar of $Z$. tuberculosa flowers was dominated by the disaccharide sucrose and its monosaccharides, fructose and glucose. The nectar was hexose-rich with overall ratio $S /(G+F)$ of $0.3 \pm 0.1$. The carbohydrate composition was $21.0 \pm 8.0 \%$ of sucrose, $39.1 \pm 3.8 \%$ of glucose and $39.9 \pm 4.2 \%$ of fructose. The $G / F$ ratio was close to $1(\mathrm{G} / \mathrm{F}=0.98 \pm 0.01)$.

\subsection{Fruit set}

The natural fruit set was $2.4 \times 10^{-5} \pm 1.4 \times 10^{-5}$ (plant $1=18$ fruits, plant $2=0$ fruits, plant $3=13$ fruits, plant $4=1$ fruit).

\section{Discussion}

Our results showed self-incompatibility in the studied plants of Zeyheria tuberculosa, indicating the need of a vector for pollen transfer among trees. In fact, $Z$. tuberculosa flowers show attributes associated to melittophily. We verified that one species of floral visitor, the medium-sized bee Bombus pauloensis, has morphological attributes and a visit behaviour that may result in the pollination of $Z$. tuberculosa flowers, although these bees showed a very low frequency of visits. Three species of small-sized bees were considered as antagonists, one of them acting as a pollen thief and two as nectar thieves. The nectar sugar composition was similar to that described for other plant species pollinated by short-tongued bees (Baker and Baker, 1983). Even though the nectar secretion pattern were close to the patterns described for other bee-pollinated Bignoniaceae species (Gottsberger and Silberbauer-Gottsberger, 2006), the nectar volume and concentration in first-day flowers were lower than that observed in second-day flowers. Although the pollinator bees visited both floral stages, in natural conditions $Z$. tuberculosa plants showed a very low natural fruit set.

Zeyheria tuberculosa flowers showed attributes associated to bee pollination, such as opening early in the morning, presenting yellow corolla and nectar guides (Willmer, 2011). The flowers showed colour change during their lifetime, which is a feature already described in the Bignoniaceae family (Weiss, 1995). This author refers that pre-change flowers have receptive stigmas and present rewards, while post-change flowers are sexually unviable and rewardless. However, in Z. tuberculosa both flower stages contained rewards and were sexually viable. Nevertheless, the colour change in $Z$. tuberculosa may have an important role in pollina- 


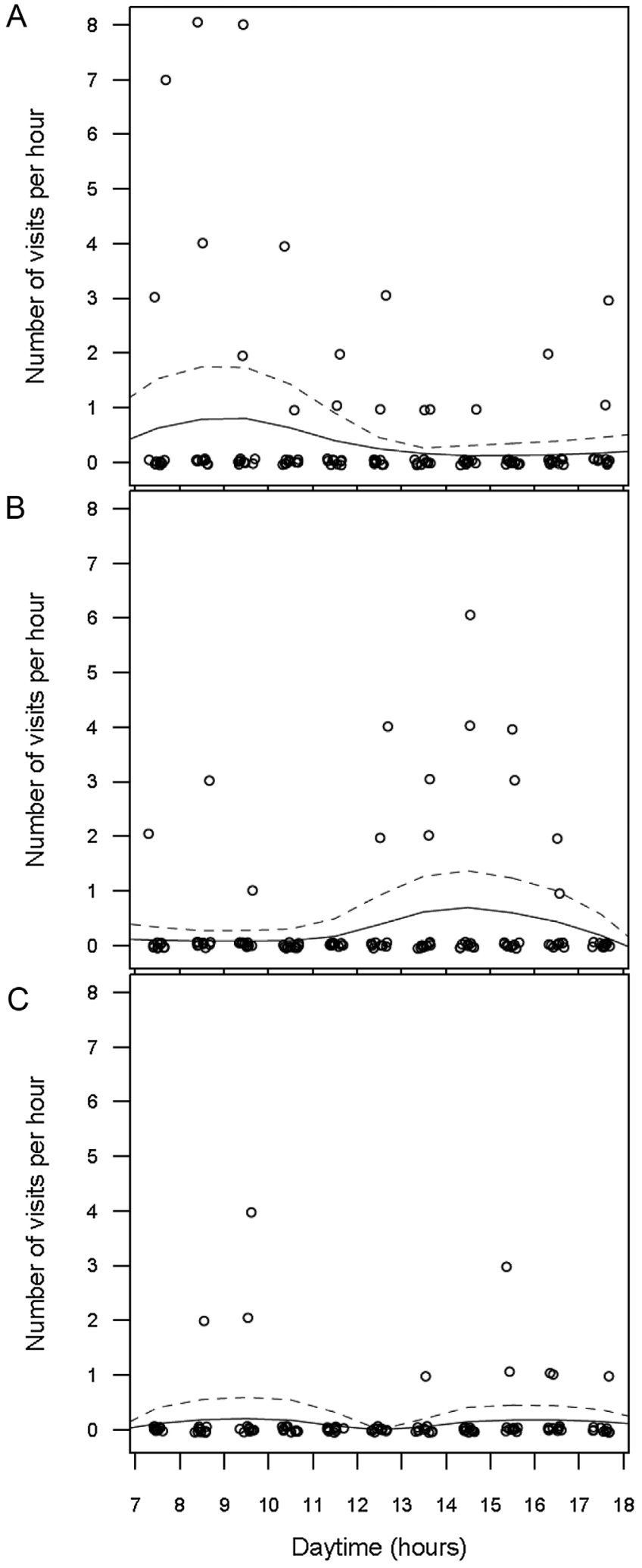

Fig. 3. Zeyheria tuberculosa bee visits distribution throughout the day $\left(\mathrm{N}_{\text {days }}=11\right)$. The trend lines describe a visual relationship between the two variables (number of visits and day time) based on the lowest smoother using a locally weighted regression (LOESS). Dashed lines are 95\% confidence interval upper limits. The 95\% confidence interval lower limits were zero and the line was omitted. (A) Number of visits of the pollinator Bombus pauloensis per hour per tree. (B) Number of visits of the pollen thief Trigona spinipes per hour per tree. (C) Number of visits of the nectar thieves Pseudoaugochlora pandora and $P$. graminea per hour per tree. tors' foraging strategy, since we observed a preference for first-day flowers (70\%), which indicates that the pollinator can (visually) discriminate young and old flowers, as referred by Weiss (1995).

The studied plants of $Z$. tuberculosa were self-sterile, similar to its only congeneric species, $Z$. montana, which possess lateacting self-incompatibility (Bittencourt and Semir, 2004). The fact that $Z$. tuberculosa is self-sterile suggests that this species relies on a vector to guarantee pollen transfer among plants, allowing outcrossing. The very low natural reproductive success registered here may be associated with this plant species self-incompatibility, since pollen limitation due to reproductive impairment may occur (Aguilar et al., 2006). The limitation on the number of compatible pairs may be intensified by the scarcity of $Z$. tuberculosa plants in the current landscape. Additionally, the low frequency of pollinator visits may represent a pollen limitation (Ashman et al., 2004), which can also be responsible for the low natural reproductive success of $Z$. tuberculosa. Moreover, little is known about how changes in the original habitat may impact plant-pollinator mutualism and consequently affect plant reproductive success (Brudvig et al., 2015), but apparently it may be related to the sensitivity of the pollinators involved (Newman et al., 2013). Our data suggest that some pollen and/or pollinator limitation may negatively influence the reproductive success of this species; however more studies on how this threatened plant species is reproducing in this changed landscape are necessary in order to design conservation strategies.

Considering the campanulate flower shape and the flower dimensions, especially tube diameter and the distance from the anthers and the stigma to the nectar chamber, the medium-sized bee $B$. pauloensis was the only floral visitor observed visiting $Z$. tuberculosa flowers that could act as pollinator. Medium-sized bees have also been described as pollination vectors for other allogamous Bignoniaceae species belonging to Tabebuia alliance (Gentry, 1974; Gottsberger and Silberbauer-Gottsberger, 2006). However, visual and chemical cues may not only attract pollinators, but also a variety of animals searching for floral rewards and acting as antagonists (Schaefer and Ruxton, 2011). This scenario seems to be very true for Bignoniaceae species that establish $75 \%$ of the interactions with cheaters (Genini et al., 2010). In fact, we observed one small-sized bee species collecting pollen in an illegitimate way, acting as pollen thief, and two small-sized bee species acting as nectar thieves in $Z$. tuberculosa flowers. Pollen thieves may promote a significant reduction of the number of male gametes that may be potentially dispersed by pollinators (Hargreaves, 2007; Hargreaves et al., 2009; Quinalha et al., 2016), negatively impacting plants' reproductive success (Carmo et al., 2004). Additionally, pollen thieves may eventually deposit pollen on the stigma surface of $Z$. tuberculosa flowers during pollen collection manoeuvres. Nevertheless, this pollen load potentially comprises mainly selfincompatible pollen (from the same flower), which may result in pollen-stigma interference as described by Barrett (2002). On the other hand, it is possible that a small-sized bee brings, adhered to its body, little amounts of pollen from other $Z$. tuberculosa plants (potentially compatible), which could reach the stigma surface at the moment that the bee lands on the flower. However, it has been demonstrated for other Bignoniaceae species that these small-sized bee visits may result in seed production, but those seeds were not viable (Quinalha et al., 2016).

Regarding nectar larceny, as thieves use the same flower opening used by pollinators (Inouye, 1980), their impact has been mostly associated to changes in pollinators' and other larcenists' behaviour, which may, negatively or positively, affect pollen flow and plant's reproductive success (Zhang et al., 2014). For example, nectar thieves may reduce plant reproductive success by decreasing floral resource to a level that might discourage pollinator visits (Irwin and Brody, 2000). Additionally, the impact of nectar and pollen thieves on the plants' reproductive success may depend 

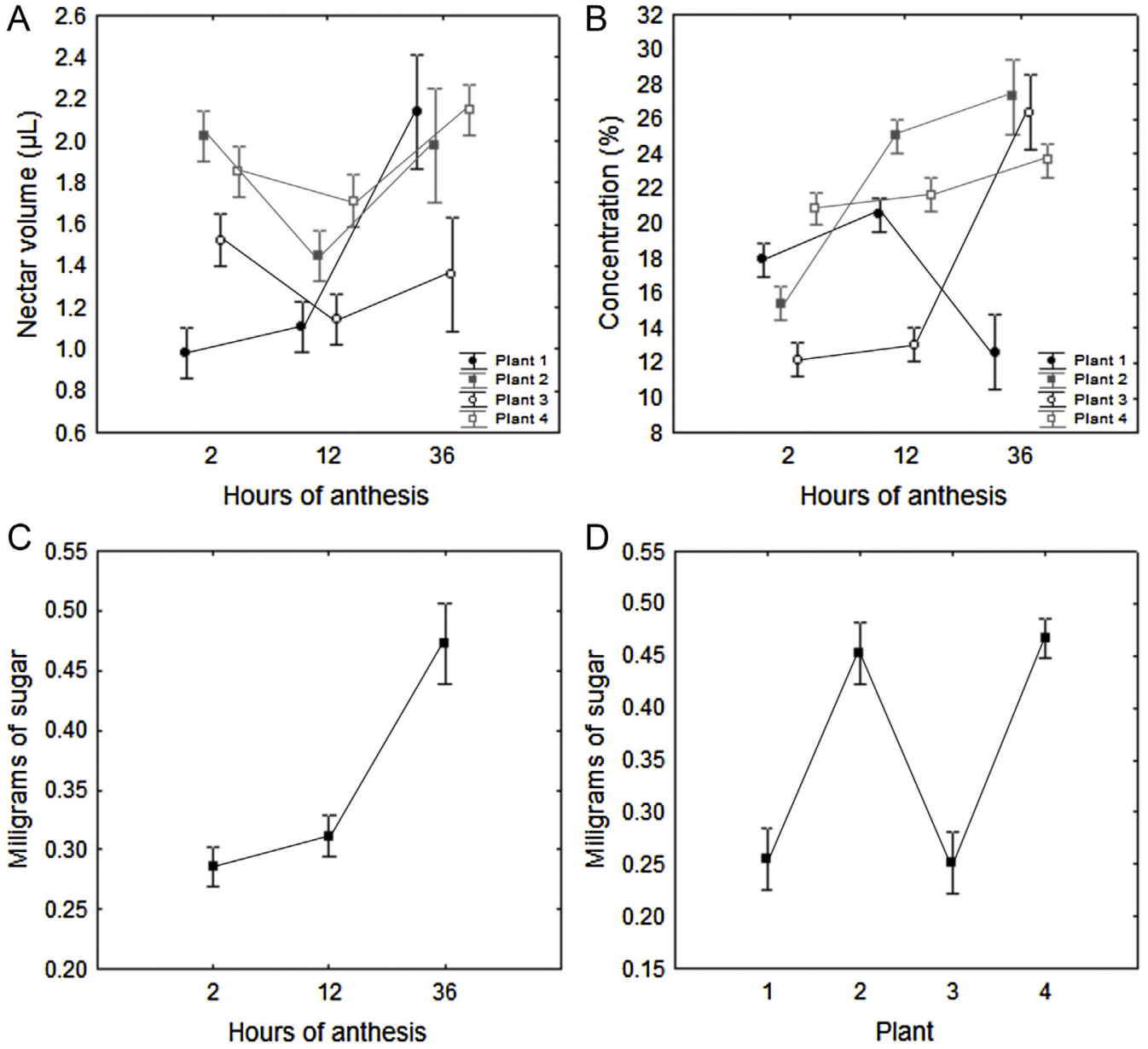

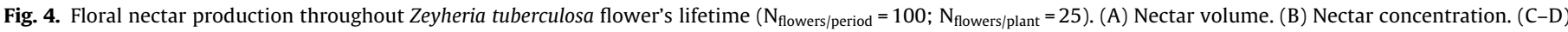

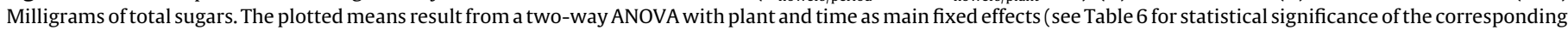
plant-time interaction effects). Vertical bars denote $+/$ - standard deviations.

on the intensity with which these interactions occur (Maloof and Inouye, 2000; Wang, 2013; Barker and Bronstein, 2016) and on the temporal sequence of antagonists and mutualists visits (Barker and Bronstein, 2016; Quinalha et al., 2016).

In our study we observed distinctive visitation patterns for each group of floral visitors, pollinators, pollen thieves and nectar thieves, throughout the day. Pollinators showed a peak in the early morning $(0800-0900 \mathrm{~h})$, pollen thieves in the mid-afternoon (1400-1600 h) and nectar thieves showed two slight peaks, one in the mid-morning (0900-1000 $\mathrm{h}$ ) and another in the mid-afternoon (1500-1600 h). Thus, the pollinators' and thieves' activity peaks were different throughout the day, only showing an overlap in the afternoon between pollen and nectar thieves' activity peaks. Nevertheless, all the bee groups were active most of the time, with the exception of the hottest hours of the day, when nectar and pollen thieves were not active. This kind of temporal structure may influence the final result of the mutualism, especially if thieves exploit resources before the pollinators, which may lead to a higher cost to the plant (Barker and Bronstein, 2016). However, in our studied system the peak of mutualists visits occurred prior to the peak of parasitic visits, indicating a lower cost to the plant (Barker and Bronstein, 2016), and also ensuring that most of the resources offered to pollinators (nectar), and the male gametes (pollen) available for reproduction, were preserved at the peak of pollinator visits.

Bees belonging to Bombus show variations concerning tongue length and can be classified as short-tongued (5-6 mm), medium- tongued (7-8 mm), long-tongued (9-10 mm) and very longtongued (14-16 mm) bees (Willmer, 2011). According to these range values, $B$. pauloensis belongs to the short-tongued category (Table 4). Thus, this bee should enter its head and thorax into the corolla tube in order to access the nectar accumulated in the nectar chamber, which is located approximately $15 \mathrm{~mm}$ deep in the corolla tube. It is remarkable that the dimensions of the diameter of the corolla mouth at the zygomorphic plan $(5.09 \pm 0.49 \mathrm{~mm})$, and the bee thorax dorsiventral thickness $(5.90 \pm 0.48 \mathrm{~mm})$ are very similar allowing a close contact of the bee body with $Z$. tuberculosa reproductive structures, during nectar gathering. This finding differs from most melittophilous Bignoniaceae species, which are probably pollinated by Bombus bees with longer tongues, as nectar is commonly stored more deeply in longer corolla tubes $(46.2 \pm 11.2 \mathrm{~mm})$ (Galetto, 2009). The campanulate-shaped corolla of $Z$. tuberculosa, associated with the short distance from the stigma and anthers to the nectar chamber, allows this medium-sized bee with short tongue to access the nectar, while contacting the reproductive structures. When this bee reaches the nectar chamber, its eyes' region, its head and the dorsal portion of its thorax contacted the anthers and the stigma, characterizing nototribic pollination, as described for other Bignoniaceae (Guimarães et al., 2008; Polatto et al., 2012). Additionally, the placement of reproductive structures in Z. tuberculosa flowers favoured allogamy in this self-sterile species by the presence of approach and movement herkogamy (sensu Webb and Lloyd, 1986). In bee visits to Z. tuberculosa, nototribic pollen deposition on the bees' bodies occurred following 
a specific sequence. First the receptive stigma surface (if the lobes are opened) was contacted by bees, and then the anthers' area; if the anthers were full of pollen it could adhere to the bees' body and be transported to the next flower. Additionally, the closure of stigmatic lobes, a few seconds after being touched, characterized the movement herkogamy, which also prevents pollen-stigma interference in several Bignoniaceae species, according to Milet-Pinheiro et al. (2009).

Nectar is the most important floral resource for the majority of Bignoniaceae, which is a family predominately composed by species having sympetalous nectariferous and zoophilous flowers (Gentry, 1992; Bittencourt and Semir, 2004; Gottsberger and Silberbauer-Gottsberger, 2006; Guimarães et al., 2008; Galetto, 2009). Commonly, the period of nectar secretion is associated to the period of pollinator activity, according to Cruden et al. (1983). Indeed, the production of floral nectar in Z. tuberculosa started before the anthesis, ensuring resource offer to pollinators at the moment of flower opening, when we registered the peak of pollinator visits, similar to what was reported by Guimarães et al. (2016) for Anemopaegma album (Bignoniaceae). Nevertheless, $Z$. tuberculosa first-day flowers present lower nectar volume and concentration $(1.61 \pm 0.27 \mu \mathrm{L}$ and $19.71 \pm 2.95 \%)$ as compared to other melittophilous species occurring in the same region as this study $(12.4 \pm 0.25 \mu \mathrm{L}$ and $30.97 \pm 5.28 \%$; Gottsberger and SilberbauerGottsberger, 2006). However, in second-day flowers the nectar concentration became similar to other bee-pollinated Bignoniaceae (Gottsberger and Silberbauer-Gottsberger, 2006). Even in secondday flowers, nectar concentration was lower than the optimum concentration referred for bumblebees, which ranges from 50 to 65\% (Pyke and Waser, 1981; Harder, 1986; Willmer, 2011). According to Harder (1986), the nectar concentration which maximizes the energy intake by bumblebees should be greater than $40 \%$ since medium-sized bees, such as $B$. pauloensis, have high energy needs. Additionally, these bees typically do not require water due to the substantial metabolic water production during flight (Nicolson, 2009). Consequently, these bees normally interact with flowers that produce little and concentrated nectar (Baker and Baker, 1983) that could reduce the metabolic problem of minimizing water load (Bertsch, 1984). Nectar sugar concentration regulation has been considered an important adaptive feature in insect-pollinated flowers, since it guarantees adequate viscosity, allowing the nectar collection by a specific mouth apparatus and maintaining the fidelity of pollinators (Baker and Baker, 1975; Nicolson, 1995; Nicolson and Nepi, 2005). It may also modulate the energy intake rate during feeding, which may influence foraging efficiency and consequently plant's reproductive success (see Borrell, 2007 and references therein).

The decrease in nectar volume and increase in nectar concentration during the daylight hours of the first day of anthesis, in Z. tuberculosa flowers, suggest the occurrence of evaporation, making nectar concentration more similar to other melittophilous Bignoniaceae trees from seasonal ecosystems in Brazil described by Gottsberger and Silberbauer-Gottsberger (2006). Tubular flowers, which are characteristic of Bignoniaceae, are considered efficient in protecting nectar quality as this floral shape only allows a small area of nectar to be in direct contact with air (Petanidou, 2005). However, Z. tuberculosa has shallower and more open campanulate flowers, which may leave a greater surface of nectar in direct contact with air, and subjected to a major effect of evaporation (Nicolson and Nepi, 2005).

Floral features related to nectar secretion are expected to vary among plants (Hodges, 1993; Herrera, 2009; Galetto, 2009). In fact, beyond the intrafloral nectar variation throughout anthesis, we also observed some variation in nectar volume and concentration among $Z$. tuberculosa plants, showing an interplant variability. The phenotypic plasticity in nectar features may be determined by resource allocation and may represent a trade-off with other plant functions, such as plant defence or vegetative growth (Rathcke, 1992). Nectar volume and concentration in flowers are the combined result of secretion rate, reabsorption, and evaporation rate (Nicolson and Nepi, 2005). Thus, predictions for these patterns are not simple because they may be related to pollinators' behaviour, environmental factors, plant resource allocation, and other factors (Galetto and Bernardello, 2004).

Nectar sugar composition has been related to the visitation of specific pollinator guilds (Baker and Baker, 1983; Petanidou, 2005; Schmidt-Lebuhn et al., 2006; Nicolson, 2007) and Z.tuberculosa nectar sugar composition is rich in hexose matching short-tongued bees' preferences according to Baker and Baker (1983). Additionally, nectar sugar composition (sucrose/hexose ratio) has been associated with climate conditions, mainly with water availability within the system (Petanidou, 2005). Summer-flowering Mediterranean species, which experience an extremely hot and dry summer season, differed significantly in nectar composition from those flowering in the wet period, showing a prevalence of highsucrose nectar (Petanidou, 2005). According to Nicolson (1998, 2002), hexose-rich nectars require more water than sucrose-rich nectars for equal amounts of carbohydrate available to pollinators. In our study the hexose-rich nectar from $Z$. tuberculosa does not represent a constraint, considering that this plant species flowers during the rainy tropical summer, and water is not a limiting factor.

\section{Conclusions}

Zeyheria tuberculosa flowers showed attributes related to melittophily, being the floral nectar secretion pattern and sugar composition close to the patterns described for other beepollinated Bignoniaceae species. Only the medium-sized bee, Bombus pauloensis, was considered as a pollinator of $Z$. tuberculosa. All the small-sized bees acted as thieves; however the temporal separation in the peaks of resource exploitation registered for the distinct groups indicated that when the peak of pollinator visits occurs, most of the nectar and the pollen load are still available to be consumed and transferred, respectively. Nevertheless, Z. tuberculosa showed low natural fruit set, which may be related to the scarcity of bee pollinator visits. This fact, associated to the need of compatible pairs in this self-incompatible species, could be of special concern for this threatened species maintenance in the medium and long term, which depends on the offspring originated by sexual reproduction.

\section{Acknowledgments}

This work was supported by 'FAPESP - São Paulo Research Foundation' [Biota Program Proc. 2008/55434-7; PD-Fellowship to E. Guimarães, Proc. 2009/17611-7]; the 'National Counsel of Technological and Scientific Development' [grant to S.R. Machado, scholarship to C. Vaz and Edital MCT/CNPq Proc. 470649/2008-9]. We thank Eduardo A. B. Almeida (FFCLRP-USP) for Augochlorini bees taxonomic identification, Anselmo Nogueira for statistical analysis support, Priscila T. Tunes for English review, Daniel Tancler for help in the schematic flower draw and the students from the 'Ecology and Evolution of Plant-Animal Interactions Laboratory' for the field support. We thank Dr. S. Dötterl, Dr. C. Herrera and the anonymous reviewer for the critical review and the valuable contribution in order to improve the manuscript.

\section{References}

Aguilar, R., Ashworth, L., Galetto, L., Aizen, M.A., 2006. Plant reproductive succeptibility to habitat fragmentation: review and synthesis through a meta-analysis. Ecol. Lett. 9, 968-980. 
Aguilar, R., Ashworth, L., Cagnolo, L., Jausoro, M., Quesada, M., Galetto, L., 2009. Dinamica de Interacciones mutualistas y antagonistas em ambientes fragmentados. In: Medel, R., Aizen, A.M., Zamora, R. (Eds.), Ecologí ia y Evolucióon de Interacciones Planta-Animal. Editorial Universitaria S.A Santiago de Chile, pp. 199-230.

Alcantara, S., Lohmann, L.G., 2010. Evolution of floral morphology and pollination system in Bignonieae (Bignoniaceae). Am. J. Bot. 97, 782-796.

Ashman, T.L., Knight, T.M., Steets, J.A., Amarasekare, P., Burd, M., Campbell, D.R., Morgan, M.T., 2004. Pollen limitation of plant reproduction: ecological and evolutionary causes and consequences. Ecology 85, 2408-2421.

Baker, H.G., Baker, I., 1975. Studies of nectar-constitution and pollinator-plant coevolution. In: Gilbert, L.E., Raven, P.H. (Eds.), Coevolution of Animals and Plants. Columbia University Press, New York, pp. 126-152.

Baker, H.G., Baker, I., 1983. A brief historical review of the chemistry of flora nectar. In: Bentley, B., Elias, T.E. (Eds.), The Biology of Nectaries. Columbia University Press, New York, pp. 126-152.

Barker, J.L., Bronstein, J.L., 2016. Temporal structure in cooperative interactions: what does the timing of exploitation tell us about its cost? PLoS Biol. 14, e1002371.

Barrett, S.C.H., 2002. Sexual interference of the floral kind. Heredity 88, 154-159.

Bertsch, A., 1984. Foraging in male bumblebees (Bombus lucorum L.): maximizing energy or minimizing water load? Oecologia 62, 325-336.

Bittencourt Jr, N.S., Semir, J., 2004. Pollination biology and breeding system of Zeyheria montana (Bignoniaceae). Plant Syst. Evol. 247, 241-254.

Borrell, B.J., 2007. Scaling of nectar foraging in orchid bees. Am. Nat. 169, 569-580.

Brudvig, L.A., Damschen, E.I., Haddad, N.M., Levey, D.J., Tewksbury, J.J., 2015. The influence of habitat fragmentation on multiple plant-animal interactions and plant reproduction. Ecology 96, 2669-2678.

Carmo, R.M., Franceschinelli, E.V., Silveira, F.A., 2004. Introduced honeybees (Apis mellifera) reduce pollination success without affecting the floral resource taken by native pollinators. Biotropica 36, 371-376

Carvalho, P.E.R., 2005. Ipê-felpudo. Embrapa Florestas. Circular técnica.112., pp. $1-9$

Chapin III, F.S., Matson, O.A., Mooney, H.A., 2002. Principles of Terrestria Ecosystem Ecology. Springer-Verlag, New York, 436p.

Cruden, R.W., Hermann, S.M., Peterson, S., 1983. Patterns of nectar production and plant-pollinator coevolution. In: Bentley, B., Elias, T.E. (Eds.), The Biology of Nectaries. Columbia University Press, New York, pp. 80-125.

Cunha, A.R., Martins, D., 2009. Atualização da classificação climática para os municípios de Botucatu e São Manuel, SP. Irriga 14, 1-11.

Dafni, A., Kevan, P.G., Husband, B.C., 2005. Practical Pollination Biology. Enviroquest, Ltd., Cambridge.

Faegri, K., Van Der Pijl, L., 1979. The Principles of Pollination Ecology. Oxford, Pergamon.

Galetto, L., Bernardello, G., 2004. Floral nectaries: nectar production dynamics and chemical composition in six Ipomoea species (Convolvulaceae) in relation to pollinators. Ann. Bot. 94, 269-280.

Galetto, L., Bernardello, G., 2005. Nectar. In: Dafni, A., Kevan, P.G., Husband, B.C. (Eds.), Pollination Ecology: a Practical Approach. Enviroquest Ltd, Ontario, pp. $156-212$

Galetto, L., 2009. Nectary and nectar features: occurrence, significance, and trends in bBignoniaceae. J. Plant Reprod. Biol. 1, 1-12.

Genini, J., Morellato, L.P.C., Guimarães, P.R., Olesen, J.M., 2010. Cheaters in mutualism networks. Biol. Lett. 6, 494-497.

Gentry, A.H., 1974. Coevolutionary patterns in Central American Bignoniaceae. Ann. Mo. Bot. Gard. 61, 728-759.

Gentry, A.H., 1980. Bignoniaceae: part I. (Crescentieae and Tourrettieae). Flora Neotrop. 25, 1-130

Gentry, A.H., 1990. Evolutionary patterns in neotropical Bignoniaceae. Mem. N. Y. Bot. Gard. 55, 118-129.

Gentry, A.H., 1992. Bignoniaceae: part II (Tribe Tecomeae). Flora Neotrop. 25, $1-370$.

Gottsberger, G., Silberbauer-Gottsberger, I., 2006. Life in the cerrado: a South American tropical seasonal ecosystem. Pollination and Seed Dispersal, vol. II. RetaVerlag, Ulm

Guimarães, E., Di Stasi, L.C., Maimoni-Rodella, R.C.S., 2008. Pollination biology of Jacaranda oxyphylla with an emphasis on staminode function. Ann. Bot. 102, 699-711.

Guimarães, E., Nogueira, A., Machado, S.R., 2016. Floral nectar production and nectary structure of a bee-pollinated shrub from neotropical savannah. Plant Biol. 18, 26-36.

Harder, L.D., 1986. Effects of nectar concentration and flower depth on flower handling efficiency of bumble bees. Oecologia 69, 309-315.

Hargreaves, A.L., Harder, L.D., Johnson, S.D., 2009. Consumptive emasculation: the ecological and evolutionary consequences of pollen theft. Biol. Rev. 84, 259-276.

Hargreaves, A.L., 2007. The Ecological Effects of Pollen-stealing Insects on Plant Reproductive Success, M.Sc. University of Calgary.

Herrera, C.M., 1990. Daily patterns of pollinator activity, differential pollinating effectiveness, and floral resource availability, in a summer-flowering Mediterranean shrub. Oikos 58, 277-288.

Herrera, C.M., 1996. Floral traits and plant adaptation to insect pollinators: a devil's advocate approach. In: Lloyd, D.G., Barrett, S.C.H. (Eds.), Floral Biology Springer, US, pp. 65-87.

Herrera, C.M., 2009. Multiplicity in Unity: Plant Subindividual Variation and Interactions with Animals. University of Chicago Press.
Hodges, S.A., 1993. Consistent interplant variation in nectar characteristics of Mirabilis multiflora. Ecology 74, 542-548

Inouye, D.W., 1980. The terminology of floral larceny. Ecology 61, 1251-1253.

Irwin, R.E., Brody, A.K., 2000. Consequences of nectar robbing for realized male function in a hummingbird-pollinated plant. Ecology 81, 2637-2643.

Kearns, C.A., Inouye, D.W., 1997. Pollinators, flowering plants, and conservation biology. Bioscience 47, 297-307.

Lohmann, L.G., Pirani, J.R., 1996. Tecomeae (Bignoniaceae) da cadeia do Espinhaço, Minas Gerais e Bahia, Brasil. Acta Bot. Bras. 10, 103-138.

Lohmann, L.G., Ulloa, C.U., 2007. Bignoniaceae. (iPlants Prototype Checklist) [online], http://www.iplants.org (Accessed 15 April 2016).

Luz, H.D.F., Ferreira, M., 1985. Ipê Felpudo (Zeyhera tuberculosa (Vell) Bur.): essência nativa pioneira com grande potencial silvicultural. IPEF Piracicaba 31, 13-32.

Maloof, J.E., Inouye, D.W., 2000. Are nectar robbers cheaters or mutualists? Ecology $81,2651-2661$

Martinelli, G., Moraes, M.A., 2013. Livro vermelho da flora do Brasil (Jardim Botânico do Rio de Janeiro), http://cncflora.jbrj.gov.br (Accessed 17 February 2016).

Milet-Pinheiro, P., Carvalho, A.T., Kevan, P.G., Schilindwein, C., 2009. Permanent stigma closure in Bignoniaceae: mechanism and implications for fruit set in self-incompatible species. Flora 204, 82-88.

Newman, B.J., Ladd, P., Brundrett, M., Dixon, K.W., 2013. Effects of habitat fragmentation on plant reproductive success and population viability at the landscape and habitat scale. Biol. Conserv. 159, 16-23.

Nicolson, S.W., Nepi, M., 2005. Dilute nectar in dry atmospheres: nectar secretion patterns in Aloe castanea (Asphodelaceae). Int. J. Plant Sci. 166, 227-233.

Nicolson, S.W., 1995. Direct demonstration of nectar reabsorption in the flowers of Grevillea robusta (Proteaceae). Funct. Ecol. 9, 584-588.

Nicolson, S.W., 1998. The importance of osmosis in nectar secretion and its consumption by insects. Am. Zool. 38, 418-425.

Nicolson, S.W., 2002. Pollination by passerine birds: why are the nectars so dilute? Comp. Biochem. Physiol. B: Biochem. Mol. Biol. 131, 645-652.

Nicolson, S.W., 2007. Nectar consumers. In: Nicolson, S.W., Nepi, M., Pacinni, E. (Eds.), Nectaries and Nectar. Springer, New York, pp. 129-166.

Nicolson, S.W., 2009. Water homeostasis in bees, with the emphasis on sociality. J. Exp. Biol. 212, 429-434.

Petanidou, T., 2005. Sugars in Mediterranean floral nectars: an ecological and evolutionary approach. J. Chem. Ecol. 31, 1065-1088

Polatto, L.P., Chaud-Netto, J., Dutra, J.C.S., Junior, V.V.A., 2012. Exploitation of floral resources on Sparattosperma leucanthum (Bignoniaceae): foraging activity of the pollinators and the nectar and pollen thieves. Acta Ethol. 15, 119-126.

Potts, S.G., 2005. Plant interface - pollinator interface: recording pollinator behaviour on flowers. In: Dafni, A., Kevan, P.G., Husband, B.C. (Eds.), Pollination Ecology: A Practical Approach. Enviroquest Ltd, Ontario, pp. 329-339.

Pyke, G.H., Waser, N.M., 1981. The production of dilute nectars by hummingbird and honeyeater flowers. Biotropica 13, 260-270.

Quinalha, M.M., Nogueira, A., Ferreira, G., Guimarães, E., 2016. Effect of mutualistic and antagonistic bees on floral resources and pollination of a savanna shrub. Flora Morphol. Distrib. Funct. Ecol. Plants, http://dx.doi.org/10.1016/j.flora. 2016.08.005.

R Development Core Team, 2016. R: A Language and Environment for Statistical Computing. R Foundation for Statistical Computing, Vienna, Austria, www.Rproject.org (Accessed 15 october 2016).

Radford, A.E., Dickison, W.C., Massey, J.R., Bell, C.R., 1974. Vascular Plant Systematics. Harper \& Row Publishers, New York.

Rathcke, B.J., 1992. Nectar distributions, pollinator behaviour, and plant reproductive success. In: Hunter, M.D., Ohgushi, T., Price, P.W. (Eds.), Effects of Resource Distribution on Animal Plant Interactions. Academic Press, pp. $113-138$.

Schaefer, H.M., Ruxton, G.D., 2011. Plant-Animal Communication. Oxford University Press.

Schmidt-Lebuhn, A.N., Schwerdtfeger, M., Kessler, M., Lohaus, G., 2006 Phylogenetic constraints vs ecology in the nectar composition of Acanthaceae. Flora 202, 62-69.

StatSoft Inc, 2013. STATISTICA (data Analysis Software System), Version 12 StatSoft, Tulsa, OK.

Wang, Y., 2013. Dynamics of plant - pollinator - robber systems. J. Math. Biol. 66, 1155-1177.

Webb, C.J., Lloyd, D.G., 1986. The avoidance of interference between the presentation of pollen and stigmas in angiosperms II. Herkogamy. New Zeal. J. Bot. 24, 163-178.

Weiss, M.R., 1995. Floral color change: a widespread functional convergence. Am. J. Bot. 82, 167-185.

Willmer, P., 2011. Pollination and Floral Ecology. Princeton University Press, Princeton.

World Conservation Monitoring Centre, 1998. Zeyheria tuberculosa (The IUCN Red List of Threatened Species.Version 2014.3), www.iucnredlist.org (Accessed 01 February 2016)

Zhang, Y.W., Zhao, J.M., Inouye, D.W., 2014. Nectar thieves influence reproductive fitness by altering behaviour of nectar robbers and legitimate pollinators in Corydalis ambigua (Fumariaceae). J. Ecol. 102, 229-237. 